\title{
The Influence of Task-based Metadiscourse Instruction on University Students' Writing Quality
}

\author{
Li CHANG \\ School of Foreign Languages, Qilu University of Technology, Jinan, China \\ lichang@163.com
}

Keywords: Metadiscourse, Metatext, Discourse markers, Hedging, Validity marker, Illocutionary.

\begin{abstract}
Recently, metadiscourse has been under study from a descriptive point of view and has been revealed to be a prominent characteristic of various types of academic text, which cover school textbooks, university textbooks, doctoral dissertations and pedagogical studies such as reading comprehension, listening comprehension and writing. It has also been investigated comparatively in order to comprehend the differences in usage across cultures. Some work has fixed the eyes on metadiscourse in composition. Nevertheless, very few studies have paid attention to the functions of metadiscourse in particular contexts and less experimental work has been carried out about the effects of metadiscourse on English writing of Chinese college students. This paper aims to evaluate a new approach of classroom metadiscourse instruction.
\end{abstract}

\section{Introduction}

Metadiscourse, often featured as "discourse about discourse, or writing about writing", is a concept familiar to many scholars engaged in research and instruction in composition, reading, and text structure. On the basis of a view of writing as a communicative and social engagement between writer and reader, the attention of metadiscourse has been focused on the ways writers were projected into their discourse to signal their attitude towards both the content and the audience of the text. Consequently, it has been taken up by corpus analysts attracted by the possibility of tracing patterns of interaction and cohesion across discourses and by researchers with functional orientations to text.

Recently, metadiscourse has been under study from a descriptive point of view and has been revealed to be a prominent characteristic of various types of academic text, which cover school textbooks, university textbooks, doctoral dissertations and pedagogical studies such as reading comprehension, listening comprehension and writing. [1] analyzed EFL (English as a Foreign Language) university students' essays and drew the conclusion that good essays used a greater variety of metadiscourse than poor ones. [2] conducted an experiment to scrutinize the effect of the targeted instruction of metadiscourse on the writing abilities of native-speaker university students.

Nevertheless, very few studies have paid attention to the functions of metadiscourse in particular contexts and less experimental work has been carried out about the effects of metadiscourse on English writing of Chinese college students. This paper aims to evaluate a new approach of classroom metadiscourse instruction.

\section{Literature Review}

Some experimental work has been done on the effects of metadiscourse on pedagogical studies. [3] attempted to determine whether including informational and attitudinal metadiscourse in social studies textbooks would affect reading retention with native speaker students. [4] investigated the effects of hedging on reading retention. [5] did exploratory classroom research with a group of Italian college students to gain further insight into the effect of metadiscourse on ESP reading comprehension. [6] tried to determine whether explicit instruction of metadiscourse markers would influence pre-intermediate EFL learners' reading comprehension skills.

Besides reading comprehension, more work has been done concerning writing. Many researchers have made attempts to investigate the contributions that metadiscourse can make to language pedagogy. Some 
studies got indirect negative results. [7] studied the roll of signaling on adult and teenager students and did not find obvious effects on their recall of expository passages; [8] found that high school students did not recall strings of metadiscourse that are attached to sentences in expository paragraphs.

Positive answers were arrived at as well. [9] carried out the experiment to study the development of writing in terms of metadiscourse used by L1 student writers and suggested that teaching students to use metadiscourse can be an effective way to improve their writing skills. [10] was endeavored in similar developmental investigation and discovered that with instruction, certain metadiscourse markers such as logical connecters were used more frequently, some such as hedges were used less frequently, but no change was detected for speech act markers. [1] aimed to find features of metadiscourse usage among good essays and drew the conclusion that skilled writers had an awareness of their readers' needs and control strategies for making their texts more considerate and accessible to their readers, while poor writers, on the other hand, failed to generate texts.

Some work was conducted under cross-culture context. By comparing the texts written by American and Finnish university students, [11] examined the cultural and gender variations in the use of metadiscourse. [12] compared the overall frequencies of adverbial connectors used by Swedish, French and British college students in their writing and discovered that the Swedish learners tended to underuse conjunctions in contrast to many EFL learners of other language backgrounds. [13] scrutinize the connectors' use in the English essay written by native and French and German EFL speakers of English and revealed the existence of universality in the cross-cultural use of certain metadiscourse features. [14] focused on the differences and similarities in Spanish- and English-speaking writers' use of metadiscourse markers. [15] did a contrastive analysis on the differences of the use of two selected metadiscourse categories, previews and reviews, both in English and Slovene research articles. [16] adopted a doubly contrastive approach and scrutinized writer manifestation in three languages of English, French and Norwegian, and three disciplines of economics, linguistics and medicine and found out that English and Norwegian represented writer-responsible cultures, while French represents were representative of a reader-responsible culture.

The above studies provide partial evidence for the universality of metadiscourse and reveal the features in the use of metadiscourse from both cross-cultural and gender-cultural perspectives. These features suggest the variations in the metadiscourse use in cultural context. Although the findings of these studies do not provide cryptically clear evidence that the presence of metadiscourse in a text improves comprehension, they do imply its facilitating role, and is therefore a topic that merits further study.

\section{Methodology}

\section{Participants}

This study was conducted in two classes: Control Class (CC) and the Experimental Class (EC), totally 82 students from Computer majors of Qilu University of Technology. The two classes had equal English level because they acquired similar scores on the pre-test, which was administered to test whether there was any difference between the two classes before the experiment.

\section{Teaching Syllabus for the Present Study}

The two classes adminitered the same textbook: New College English Integrated Course. This book collects the essays on a variety of subjects which are written in different genres by well-known writers. The editor of this book attempted to connect reading and writing activities in each unit, which is helpful to the experiment. However, the different teaching approaches were adopted in the two classes. In the Control Class, the instructor still adopted the conventional method: the students read selections from the textbooks and then analyze and discuss them. Their attention was then addressed to the subject matter of the text. Furthermore, they completed exercises about problematic structures and sentences in the textbook.

This phase of the experiment lasted for the whole academic year and throughout the whole year, for every reading class hour, 15 minutes was left for the instruction of metadiscourse theory to the students with the task-based learning (TBL) model offered by [17]. Vande Kopple's theory was adopted to assist to learn concepts, types and functions of metadiscourse. The researcher introduced basic ideas of 
metadiscourse devices and explicated the category and the functions in a text so that students had the general idea of what metadiscourse was about. This was the pre-task phase.

Table1 TBL model

\begin{tabular}{|l|l} 
The pre-task phase & Before the task, the instructor will discuss the topic with the class.
\end{tabular} Useful or relevan lexical items may be given. Also, the students may be provided with further input, such as a recording of someone doing a similar task or part of an authentic text as a warm-up. During the pre-task stage the students will have their schemata activated, and granted the opportunity to become personally involved in the lesson.

\begin{tabular}{l|l|l}
\hline The task phase & task & the students perform the task \\
\cline { 2 - 3 } planning & $\begin{array}{l}\text { the learners make preparations for report to the whole } \\
\text { class, both orally or in writing how they did the task }\end{array}$ \\
\cline { 2 - 3 } The post-task phase & analysis & $\begin{array}{l}\text { the reports are presented to the class and results are } \\
\text { compared }\end{array}$ \\
\cline { 2 - 3 } & $\begin{array}{l}\text { learners examine the recording or text for new lexical } \\
\text { items or structures }\end{array}$ \\
\hline practice & $\begin{array}{l}\text { The instructor conducts a practice of the new items either } \\
\text { during the analysis or after. }\end{array}$ \\
\hline
\end{tabular}

During the task phase, the students were supposed to find the metadiscourse devices in small groups. And unless the instructor plays a particular role in the task, his role is typically limited to observer or counselor, thus making a more student-centered methodology.

The students prepared either a written or oral report to present to the class after they completed the task phase. The instructor either posed questions or simply monitored the students. The students then presented this information to the class. The instructor here provided written or oral feedback, as appropriate. Focus then was returned to the teacher who reviewed what happened in the task. It included metadiscourse devices used by students, problems occurring to students, and perhaps the metadiscourse markers that need to be covered more or were not used enough. To make sure that students grasped the knowledge of metadiscourse markers, exercises were designed. In each session, the researcher explicated on metadiscourse markers, and as the learners were reading the course-required passages, they were required to spot the metadiscourse devices and recognize to which category they belonged. Sometimes, they were also provided metadiscourse-free texts to fulfil by suggesting the right elements or texts with unnecessary metadiscourse markers through pointing out the redundancy. However, as [18] noted, knowledge of a learning strategy is not sufficient and students must have the motivation to use it. Effectively applying reading strategies can lead to a sense of control that enhances self-efficacy and spur to apply the strategy [19].

\section{Results and Discussion}

\section{The Positive Effect of Direct Teaching of Metadiscourse on Students' Writing Ability}

The writing quality for both $\mathrm{CC}$ and $\mathrm{EC}$ has been improved, but the pace of $\mathrm{CC}$ is not as much as for EC. The improvement of $\mathrm{CC}$ could be explained as normal improvement through the conventional way of learning. The achievement gap between the two classes could be depicted as the subjects' deficiency in using metadiscourse markers in an effective manner on their own for CC. This implies that teaching students to use metadiscourse is a useful way to promoting their writing skills. One justification for this phenomenon can be that the students with the knowledge of metadiscourse can recognize different types of metadiscourse markers, interpret their performing functions, and use metadiscourse in a more proper way so that the framework of their texts is better organized. They know how to arrange the introduction, the body or conclusion of a text; they also know what expressions to use to imply the shift of topic; they know how to develop their ideas as well. 
The second explanation is that teaching students to use metadiscourse makes them more sensitive to the needs of readers and they begin to consider the text from the perspective of potential readers. They emphasize metadiscourse use and explore into its effects on the reader, which makes them more reflective about what to say and how to say it. They begin to pay attention to the needs of the readers i.e., their essays are more reader-friendly.

The third reason is that the metadiscourse knowledge assists the students who receive instruction on metadiscourse in their revising process. The knowledge of metadiscourse places them in a position to judge whether they have used excessive metadiscourse that might compromise their primary intention, whether they have not used enough metadiscourse and thus produced unfriendly texts or whether they have used metadiscourse inappropriately. Also, It is easier for them not only to jump at the problems but also come up with specific solutions by knowing the terminology of metadiscourse.

\section{Effects of Metadiscourse Devices on Writing Quality}

There is no significant correlation between the use of textual metadiscourse devices and the quality of writing. The results in this study suggest that textual connectives as a means to achieving coherence in writing do not significantly affect the quality of writing.

There is no obvious connection between the validity marker use and the quality of writing. It is true that proper use of validity markers will render the validity to the proposition and therefore more acceptable, but the quality of an argumentative essay is dependent more on its global persuasiveness, topic development, textual coherence, etc. Even if a writer makes well-grounded propositions and reasonable evaluation, but without logical organization and elaboration of ideas, and skilled language proficiency, he still could not write good articles.

As to the relationship between the use of attitudinal markers and the quality of writing, a negative relationship is found. This finding can be interpreted as in the following: Attitudinal markers motivate the writer's attitudinal inclination to certain extent, and contribute to making the writer's position more explicit. With these markers, it is much easier for readers to comprehend the intention of the writer and to identify the writer's position. However, these markers in general do not facilitate the development of ideas. Nor can they take the place of the role of proper choice of words and expressions, development of logic and discourse coherence, which are generally thought to be fundamental to the quality of composition. Further, excessive usage of attitudinal markers in argumentative essays may seem to be too subjective and personal, which will inevitably impair the quality of the text.

A negative but weak correlation is found between the use of illocutionary markers and the writing quality. Two cogent justifications for this could be spotted. Firstly, writing is different from speech. In a face-to-face communication, one needs to put across his intention or illocutionary force clearly, because human beings are not capable of memorizing things and cannot retrieve all of the previous information. Therefore, in spoken discourse, illocutionary markers are needed more often to guide the addressee to apprehend the addressor's ideas [20]. By contrast, in writing, the purpose of the article can be read or inferred from between lines. Therefore, first, illocutionary markers are sufficient but not necessary conditions for indicating writers' intention; second, the overuse of illocutionary markers can only make the text sound superficial and leaves no room for readers themselves to test their thinking ability and to exercise their interpreting capacity.

\section{Conclusion}

A conventional language classes model PPP has long been adopted. With this model individual language items (for example, the present perfect tense) are presented by the instructor, then practiced in the form of oral and written exercises, and then used by the learners in less controlled oral or writing activities. Nevertheless, as to the metadiscourse teaching, direct teaching of metadiscourse can have be effective on students' writing ability and TBL model is proved to be a useful model appled in classroom.

No prominent connection between the use of textual metadiscourse devices and validity markers and the quality of writing is found. There is also no significant correlation between the use of validity markers and the quality of writing. However, as to the correlation between attitudinal markers use and the writing quality, a negative correlation is found. And a negative but weak correlation is found between the use of 
attitudinal markers and the writing quality. This result shows that the quantity of metadiscourse usage does not determine the quality of writing.

This paper provides profound insight into the study of metadiscourse and English writing instruction for EFL learners. Nevertheless, there are still deficiencies for the present study. First of all, considering the large number of EFL learners in China but the small sample available in this study, this study only included the students in Qilu University of Technology, which is far from being representative enough of the whole Chinese backdrop. Future researches with large samples can cover the students from universities across China. Secondly, the present study uses the cross-sectional study method which suffers some methodological insufficiencies of the design itself. For example, the subjects vary from each other and hence, the developmental perspective is not as reliable as it is.Thirdly, to obtain a more reliable result, more writing tasks could be administered and more devices can be revealed used by learners.

\section{Reference}

[1] Intaraprawat, P. and Steffensen, M. (1995). The Use of Meta-discourse in Good and Poor ESL Essays [J]. Journal of Second Language Writing, 4: 253-272.

[2] Steffensen, M., and Cheng, X. G. (1996). Metadiscourse and Text Pragmatics: How Students Write after Learning about Metadiscourse [J]. Research in the Teaching of English, 30 (2), 149-181.

[3] Crismore, A. (1989). Talking with Readers: Metadiscorse as Rhetorical Act [M]. New York: Peter Lang.

[4] Crismore, A. and Vande Kopple, W. (1997). Hedges and Readers: Effects on Attitudes and Learning [A]. In Markkanen, S. and Schroeder, H. (Eds.), Hedging and Discourse: Approaches to the Analysis of a Pragmatic Phenomenon in Academic Texts [C], 83-114. Berlin: Walter de Gruyter and Co.

[5] Camiciottoli, B. (2003). Metadiscourse and EAP Reading Comprehension: An Exploratory Study [J]. Reading in a Foreign Language, 15(1): 28-44.

[6] Alipour, A. J. M. (2007). How Explicit Instruction Maks a Difference: Metadiscourse Markers and EFL Learners' Reading Comprehension Skill (J) . Journal of College Reading and Learning, 38 (1): $35-52$.

[7] Meyer, B., Brandt, D. and Bluth, G.. (1980). Use of Toplevel Structure in Text: Key for Reading Comprehension of Ninth-grade Students [J]. Reading Research Quarterly, 16: 72-102.

[8] Vande Kopple, W. (1980). Experimental Evidence for Functional Sentence Perspective [D]. Unpublished Doctoral Dissertation, University of Chicago.

[9] Cheng, X. and Steffensen, M. (1997). Meta-discourse: A Technique for Improving Student Writing [J]. Research in the Teaching of English, 30(2): 149-181.

[10] Shaw, P. and Liu, E. (1998). What Develops in the Development of Second Language Writing [J]. Applied Linguistics, 19(2): 225-254.

[11] Crismore, A., Markkanen, R., and Steffensen, M. (1993). Metadiscourse in Persuasive Writing: A Study of Texts Written by American and Finnish University Students [J]. Written Communication, 10(1): 39-71.

[12]Altenberg, B. and Tapper, M. (1998). The Use of Adverbial Connectors in Advanced Swedish Learners' Written English [A]. In Granger, S. (eds.), Learners' English on Computer [C]. London and New York: Longman.

[13] Granger, S. (1997). Connectors Usage in the English Essay Writing of Native and Non-native EFL Speakers of English [A]. Chinese University of Hong Kong Seminar.

[14] Sáez, F. (2003). Culture in Writing [M]. Published in Tadea seu liber de Amicitia. 
[15] Peterlin, A. (2005). Text-organising Metatext in Research Articles: An English-Slovene Contrastive Analysis [J]. English for Specific Purposes, 24(3): 307-319.

[16] Dahl, T. (2004). Textual Metadiscourse in Research Articles: A Marker of National Culture or of Academic Discipline [J]. Journal of Pragmatics, 36(10): 1807-1825.

[17] Willis, J. (1996). A Framework for Task-Based Learning [M]. Longman Addison-Wesley.

[18] Dembo, M. (1994). Applying Educational Psychology [M]. NY: Longman.

[19] Pintrich, P., and Schunk, D. (1996). Motivation in Education: Theory, Research, and Application [M]. Englewood Cliffs, NJ: Prentice Hall.

[20] McCarthy, M. (1998). Spoken Language and Applied Linguistics [M]. Cambridge: Cambridge University Press. 